\title{
Green Bonds and Diversified Interest Rates
}

\author{
Julia M. Puaschunder ${ }^{1,2}$ \\ ${ }^{1}$ The New School, Department of Economics, School of Public Engagement, New York, NY 10003, USA, \\ Julia.Puaschunder@newschool.edu,www.juliampuaschunder.com \\ ${ }^{2}$ Columbia University, Graduate School of Arts and Sciences,Julia.Puaschunder@columbia.edu, \\ http://blogs.cuit.columbia.edu/jmp2265
}

\begin{abstract}
The climate change crisis has gained unprecedented urgency in the most recent decade. Overall, climate change has already led to and will continuously lead to irreversible tipping points and lock-ins that will degrade the common welfare. When taking a closer look at the macroeconomic growth prospects as measured in Gross Domestic Product (GDP), climate change gains and losses will be distributed fairly unequally throughout the world. A climate change winners and losers index generated the economic prospects under climate change around the world. The index attributed economic gain and loss prospects based on the medium temperature per country in relation to the optimum temperature for economic productivity and the GDP composition per country in order to determine how far countries are deviating from their optimum productivity levels on a time scale. As economic gains and losses from a warming earth are distributed unequally around the globe, ethical imperatives lead to the pledge to redistribute gains to losing territories in the quest for climate justice. Climate justice comprises fairness between countries but also over generations in a unique and unprecedented tax-and-bonds climate change gains and losses distribution strategy. Climate change winning countries are advised to use taxation to raise revenues to offset the losses incurred by climate change. Climate change losers could raise revenues by issuing bonds that have to be paid back by taxing future generations. Regarding taxation, within the winning countries, foremost the gaining GDP sectors should be taxed. Climate justice within a country should also pay tribute to the fact that low- and high-income households share the same burden proportional to their dispensable income, for instance enabled through a progressive carbon taxation. Those who caused climate change could be regulated to bear a higher cost through carbon tax in combination with retroactive billing through inheritance tax to map benefits from past wealth accumulation that potentially contributed to global warming. A novel policy recommendation for enacting climate justice entails diversified interest rate regimes for climate bonds repayment based on the country's initial position on the climate change gains and losses index spectrum. Diversified repayment of bonds is a new method aimed at ensuring to share the burden but also the benefits of climate change within society in an economically efficient, legally equitable and practically feasible way.
\end{abstract}

KEYWORDS: Climate Change, Economics of the Environment, Environmental Justice, Environmental Governance, Green New Deal, Healthcare, Monetary Policy, Multiplier, Social Justice, Sustainability

\section{Climate change winners and losers around the world}

Climate change has become reality. In the very many contemporary writings about global warming, the discussion has been centered around the negative impacts of climate change. The burden of climate change has been thematized and cost sharing strategies heatedly debated. The need for fairness in sharing the burden of climate change has been argued to considering national economies, the world society but also balance inbetween generations. In the current frustration over the neglect of interest in ratifying intergovernmental climate agreements, the contemporary climate negotiations may be stuck in the one-sided grilling to share burden lowering participation motivation. Unraveling the unprecedentedly described benefits arising from a warming earth may help build a more whole-rounded participatory incentive structure. State-of-the-art welfare function measurements and economic productivity parameters become the basis for conclusions about a fair spread of the gains and benefits from a warming earth. Contemporary Gross Domestic Product (GDP) measurements serve as basis for estimations about the productivity of the 
agriculture, industry and service sectors around the world. Based on the cardinal temperatures for the agriculture, industry and service sectors productivity, the average temperature per country around the world as well as climate projections of the year 2100 under the business as usual path, Puaschunder (2020b) revealed climate winners and losers around the world.

Overall and simply seen from a narrow-minded GDP perspective, the world will macroeconomically benefit more from climate change until 2100 than lose. Winning and losing from a warming earth is significantly positively correlated with the Paris COP 21 emissions country percentage of Greenhouse Gas (GHG) for ratification, leading to the conclusion that the countries that have the longest time horizon regarding a warming earth also lack motivation to mitigate global climate change based on the short-term benefits.

Following ethical considerations of Immanuel Kant's categorical imperative and John Rawls' veil of ignorance, the climatorial imperative was formulated to advocate for the need for fairness in the distribution of the global earth benefits among nations based on Kant's imperative to only engage in actions one wants to experience themselves being done to oneself. Passive neglect of action on climate mitigation is an active injustice to others.

While the method to measure the gains from climate change can certainly be refined in future studies, shedding light on climate change winners and losers is opened the gates for policy work to settle for a right, just and fair distribution of benefits and gains from our common warming mother earth. The introduction of the gains from climate change is a novel approach that should solely be seen in connection to the imperative to distribute the gains in a fair manner among all world inhabitants and as means to hopefully draw attention to climate change to agnostic market actors or those who shy away from action given the overall negative connotation of burden sharing and loss aversion.

\section{Climate justice implementation: Climate change winner transfer grantors}

The implementation of climate stability accounts for the most challenging contemporary global governance predicament that seems to pit world countries but also today's generation against future world inhabitants. In a trade-off of economic growth versus sustainability, a broad-based international coalition could establish climate stability. As a novel angle towards climate justice, the attention to global warming gains and losses being distributed unequally around the globe allows to propose to search for a well-balanced climate mitigation and adaptation public policy mix guided by micro- and macroeconomic analysis results. A new way of funding climate change mitigation and adaptation policies but also the transition to renewable energy through broad-based climate stability bonds-and-taxation mix that also involve future generations (World Bank 2015a, b).

Having shed light on the gains of a warming earth demands for the redistribution of climate change benefits to those areas of the world that will be losing from a warming earth. In the implementation, a climate change bonds but also taxation strategies are recommended. Having found that there are gains from a warming earth demands to transfer benefits into areas of the world that will be primarily losing from climate change. In order to avoid governmental expenditure on climate change hindering economic growth (Barro 1990); the climate transfers should be enacted through bonds and taxes.

Technological innovations are usually a result of a mix of private and public activities. The public sector can set frameworks and incentives, to support inventions through R\&D and de-risk of innovation through public support and subsidies and setting incentives. Public actions - such as tax and subsidies but also bonds - enable the transition to a low carbon economy, and contributing to a faster transformation of the energy system toward a less carbon-based energy provisions.

Portfolio and hedge fund managers strive for reducing risks to the overall portfolio, in the short and the long run. Renewable energy appears as crisis-stable market option as for 
being chosen in a quasi-religious act based on values and not on profit motives. Investment options based on renewable energy can reduce the risks and political dependencies on commodities associated with non-renewables.

First Jeffrey Sachs (2014) proposed an intergenerational burden sharing idea by presenting a 3-model climate change burden sharing through fiscal policy with bond issuing in order to reflect the implementation regarding contemporary finance and growth models with respect for maximizing utility of the model. In an overlapping-generations type model, research should elucidate climate change abatement and mitigation policies to lead to a fairer solution across generations. The current generation mitigates climate change and provides infrastructure against climate risk financed through climate bonds to be paid by future generations. Since for future generations the currently created externalities from economic activities - the effects of $\mathrm{CO}_{2}$ emissions - are removed, this entails that the current generations remain financially as well off as without mitigation while improving environmental well-being of future generations. As Sachs (2014) shows, this intergenerational tax-and-transfer policy turns climate change mitigation and adaptation policy into a Pareto improving strategy. Shifting the costs for climate abatement to the recipients of the benefits of climate stability appears as novel, feasible and easily-implementable solution to nudge many overlapping generations towards future-oriented loss aversion in the sustainability domain (Puaschunder 2018).

One of the most prominent forms to create revenues for public long-term investment causes are taxes. Taxation is codified in all major societies and a hallmark of democracy. Aimed at redistributing assets to provide public goods and ensure societal harmony, taxation improves societal welfare and fairness notions within society. Tax compliance is a universal phenomenon based on cooperation in the wish for improving the social compound. Taxpayers voluntarily decide to what extent to pay or avoid tax that limit the personal freedom. In a social dilemma, individual interests are in conflict with collective goals. From a myopic economic perspective, the optimal strategy of rational individuals would be to not cooperate and thus evade tax. Short-term the single civilian tax contribution does not make a significant difference in the overall maintenance of public goods - if only a few taxpayers evade taxes, public goods will not disappear or be reduced. But if a considerable number of taxpayers do not contribute to tax over time, common goods are not guaranteed and ultimately everyone will suffer from suboptimal societal conditions (Dawes 1980; Stroebe \& Frey 1982). Contemporary economic research has focused on costs and risks of tax evasion (Tyler \& De Cremer 2006). Coercive means - such as audits and fines - were found to crowd out tax morale and ultimately result in greater noncompliance as people feel controlled and not being trusted (Cialdini 1996; Feld \& Frey 2002; Frey 1992; Hasseldine 1998). In the last decade, researchers have started to recognize the importance of incorporating morals and social dynamics in economic theory on tax behavior (Andreoni, Erard \& Feinstein 1998). When analyzing tax behavior, recently behavioral economics insights have drawn attention to social influences (Puaschunder 2020a).

Behavioral economists widen the lens of incorporating sociological and socio-psychological notions of fairness stemming from social comparisons regarding tax burdens could be positive drivers of tax compliance to overcome the 'burden of taxes' and associations of losses. The cases of voluntary, self-chosen tax ethics and situational influences on social tax compliance norms have just recently been covered by behavioral approaches towards public administration. In general, social comparisons determine social norms that define internalized standards how to behave. Yet internalized social norms are based on comparisons with others that may determine tax morale (Frey 1997; Mumford 2001; Schmölders 1960). Social norms elicit concurring behavior when taxpayers identify with the goals of a group but also if they feel being treated in a fair manner by that group. Social fairness considerations in a tax reference group may further taxpayer compliance. Fairness is believed to decrease egoistic utility maximization leveraging trust and reciprocity as interesting social norms building factors (Kirchler 2007). Social perceptions of fairness as underlying social norms are therefore potential tax ethics nudges. But 
psychological facets of fairness for the formation of social norms have been left out. If taxpayers believe that non-compliance is a widespread and socially-accepted, then it is more likely that they will not comply as well. Non-compliance may stem from the notion of unfairness in how the tax burden is weighted heavier on some parts of society.

The respective bonds-and-tax climate stability financing strategy therefore proposes to bear the burden of climate in a right, just and fair way around the globe. In the climate change winner countries, taxation should become the main driver over financing climate stability strategies. Foremost, the industries winning from a warming climate should be taxed. The Winner-Loser-index is based on the cardinal temperatures for all GDP contributing sectors. Based on the cardinal temperatures for the three GDP components agriculture, industry and service, the taxation should be enacted for those sectors having most time ahead. The rational is that these sectors will be gaining the most from a warming earth and will therefore be flourishing.

The taxation models should aid to share the burden of climate change within society in a fair way. Regarding concrete climate taxation strategies, a carbon tax on top of the existing tax system should be used to reduce the burden of climate change and encourage economic growth through subsidies (Chancel \& Piketty 2015). Within a country, high and low income households should face the same burden of climate stabilization adjusted for their disposable income. First, climate justice within a country should pay tribute to the fact that low- and high-income households share the same burden proportional to their dispensable income, for instance enabled through a progressive carbon taxation. Those who caused climate change could be regulated to bear a higher cost through carbon tax in combination with retroactive billing through inheritance tax. But also developed and underdeveloped countries as well as various overlapping generations are affected differently. Besides progressive taxation schemes to imbue a sense of fairness in climate change burden sharing, inheritance taxation is also a flexible means to reap past wealth accumulation, which potentially caused environmental damage. The burden of climate change mitigation and adaptation could also be allocated in a fair way within society through contemporary inheritance tax in order to reap benefits of past wealth accumulation.

In addition, finding the optimum balance between consumption tax adjusted for disposable income through a progressive tax scheme will aid to unravel drivers of tax compliance in the sustainability domain. If climate taxation is perceived as fair and just allocation of the climate burden, this could convince tax payers to pay one's share. A novel 'service-and-client' atmosphere could promote taxpayers as cooperative citizens who are willing to comply if they feel their share as fair contribution to the environment. Taxpayers as cooperative citizens would then be willing to comply voluntarily following the greater goal to promote taxpayer collaboration and enhance tax morale in the environmental domain. International comparisons of tax behavior also reveal tax norms being related to different stages of institutional development of the government, which is an essential consideration in sharing the climate change burden in a fair manner between countries. A completely novel approach is to shed light on the benefits of a warming earth in order to derive fair climate gains distribution strategies around the world (Puaschunder 2020b).

\section{Climate justice implementation: Climate change loser transfer beneficiaries}

Introducing financing climate change mitigation through bonds to be paid back by future generations through taxation is a means to raise funds for offsetting the losses of global warming. As a novel way to amend individual saving preferences in favor of future generations, Sachs (2014) proposes to mitigate climate change by debt to be repaid by tax revenues on labor income in the future. In a 2-period model, one generation works in period 1 and retires in period 2. Part of the disposable wage income is saved for consumption in the second period. $\mathrm{CO}_{2}$ emission mitigation imposes immediate costs onto current generations and reduces 
wages. Greenhouse gas concentrations in period 2 are determined by the emissions in period 1. Wages of the young in the second period are reduced by climate change dependent on greenhouse gas levels. Disposable labor income of the young equals market wage net of taxes. Leaving the current generation with unchanged disposable income allocates the burdens of climate change mitigation across generations without the need to trade off one generation's well-being for another's.

While today's young generation is left unharmed, the second period young generation is made better off ecologically. The bonds solution should be pursued in climate change loser countries, in order to offset the costs for climate change in a more intergenerationally harmonious way. Since the majority of GDP contributing factors is losing in climate change loser countries, future generations should be serving as last resort to pay for climate stability. While future generations enjoy a favorable climate and averted environmental lockins; the current populace does not face drawbacks on economic growth (Puaschunder 2019a, b). All generations are better off with mitigation through climate bonds as compared to the business-as-usual (BAU) non-mitigation scenario (Sachs 2014).

Governments in loser countries should receive tax transfers in the present from the winning countries. Since here borrowing equals loans or issuing of bonds to be paid back by future generations, the government must pay back debt plus interest payments by raising taxes on later generations. Taxing future generations is justified as for the assumed preferences of future generations to avoid higher costs of climate change long-term damages and environmental irreversible lock-ins Overall, this tax-and-transfer mitigation policy thus appears as a Pareto-improving fair solution across the world and generations.

\section{Climate justice implementation: Green bonds with diversified interest rate}

Green bonds have become fundamental pillars to raise funds for a transition to renewable energy. Solar power and wind turbines, eco-friendly infrastructure and more research and development in clean energy and green technology are all investments for climate change, which have been funded by bonds. The financialization of climate justice are estimated to comprise of 5-7\% of the contemporary world GDP, accounting for 5-6 billion USD.

The Green New Deal and the European Green Deal in combination with the European Sustainable Finance Taxonomy are all efforts to marry the idea of economic growth in line with the natural resources. Green bonds could fund all these endeavors and are currently pegged to governmental aid in the post-COVID-19 crisis recovery aid. Governments can also bring back the financial world in the service of improving and stabilizing the real economy in a stricter separation between investment and consumer banks, which already began in the course of the regulations following the 2008/09 recession. Central bank could offer diversified interest rates. Low key interest rate for driving innovation and economic growth in the financial sector that refunds higher interest rates for the real economy savings for consumers in order to avert psychosocial friction from individual over-indebtedness in households.

Based on the climate change winners and losers index, global governance could determine climate change transfer grantors and beneficiaries of climate bonds. Climate bonds could thereby feature a combination of climate justice between countries and over time. On a yearly basis, countries already determine their greenhouse gas emissions levels, hence their causing of the climate change problem. Being a climate change winner or loser should also be integrated into an index based on the greenhouse gas emissions per country in relation to other countries. The two factors of being a climate change winner or loser but also the current greenhouse gas emissions should determine a key to estimate the transfer need. Based on this index, the redistribution scheme could be enacted via a diversified interest rate, in which the climate change winners should face a lower interest rate, which will spark capital mobility in territories that gain economically from climate change. In countries that already face 
economically declining prospects due to climate change, the interest rate for climate bonds should be higher compared to climate change winners. In addition, the diversified interest rate of the climate bonds should depend on the greenhouse gas emissions levels of countries. High greenhouse gas emitting countries that are contributing more to the problem should be paying more for climate stability and hence face a lower interest rate. Lower greenhouse gas emitting countries should be beneficiaries of a higher interest rate for common green bonds. This will ensure that countries - despite having the prospect to gain from global warming are incentivized to keep their greenhouse gas emissions at a low level.

\section{Conclusion}

Climate justice accounts for the most challenging global governance goal. In the current postCOP21 Paris agreement climate change mitigation and adaptation efforts, the financialization of the ambitious goals has leveraged into a blatant demand. In the weighting of the burden of global warming, the benefits of a warming earth have been neglected since recently.

Following the introduction of the gains from climate change, a macroeconomic model was proposed to distribute the benefits of a warming earth in a fair way based on which countries are losing and which countries are winning from a warming earth until the year 2100. A fair global warming benefits distribution that grants climate justice around the world and over time was introduced that included a tax-and-bonds transfer strategy. A macroeconomic cost-benefit analysis thereby aids to find the optimum solution on how to distribute climate change benefits and burden within society and over time. When unidimensionally focusing on estimated GDP growth given a warmer temperature, over all calculated models assuming linear, prospect or hyperbolic gains and losses, the world will be gaining more than losing from a warming earth until the year 2100. Based on the $W L$ index of 188 countries of the world, less countries $(n=78)$ will gain more from global warming until 2100 than more countries $(n=111)$ will lose from a warming earth. Based on the overall WLTT index factored by GDP per inhabitant, global warming benefits are demanded to be redistributed in a fair way to offset climate change loser countries for climate change mitigation and adaptation efforts and in order to instigate a transition into renewable energy.

Adding onto contemporary climate fund raising strategies ranging from emissions trading schemes (ETS) and carbon tax policies as well as financing climate justice through bonds as viable mitigation and adaptation strategies; climate justice is introduced to comprise of fairness within a country but also among different nation states and over time in a unique and unprecedented tax-and-bonds climate change gains and losses distribution.

Thereby, climate change winning countries should be using taxation to raise revenues to offset the losses incurred by climate change. Climate change losers could raise revenues by issuing bonds that have to be paid back by taxing future generations. Regarding taxation, within the winning countries, foremost the gaining GDP sectors should be taxed.

Climate justice within a country should also pay tribute to the fact that low- and highincome households share the same burden proportional to their dispensable income, for instance enabled through a progressive carbon taxation. Those who caused climate change could be regulated to bear a higher cost through carbon tax in combination with retroactive billing through inheritance tax.

The most novel innovation would be climate change bonds that offer a diversified interest rate regime based on the starting point on the climate change winners and losers index as well as the self-reported greenhouse gas emissions. An overall redistribution key could determine per country transfers based on the climate change winner or loser status as well as the contribution to the climate change problem in their greenhouse gas emissions. The interest rate of a commonly shared bond could feature either a high or low interest rate in order to incentivize market actors strategically. A high interest rate should be offered for countries 
with climate change losing prospect as well as low greenhouse gas emissions. Moderate interest rates should be given to countries in the middle of the climate change winners and loser index spectrum as well as medium rates of greenhouse gas emissions. A low interest rate should be issued to countries that are high climate change winners on the winers and loser index spectrum as well as have high rates of greenhouse gas emissions. All these measures would ensuring to share the burden but also the benefits of climate change within society in an economically efficient, legally equitable and practically feasible way.

\section{References}

Andreoni, J., Erard, B. \& Feinstein, J.S. 1998. „Tax compliance.” Journal of Economic Literature 36(2): 818-860.

Barro, R. 1990. "Government spending in a simple model of endogenous growth." Journal of Political Economy 98: 103125.

Chancel, L. \& Piketty, Th. 2015. Carbon and inequality: From Kyoto to Paris. Paris, France: Paris School of Economics.

Cialdini, R.B. 1996. "Social influence and the triple tumor structure of organizational dishonesty." In D.M. Messick and A.E. Tenbrunsel (Eds.), Codes of conduct, pp. 44-58. New York: Sage.

Dawes, R.M. 1980. "Social dilemmas.” Annual Review of Psychology 31(1): 169-193.

Feld, L.P. \& Frey, B.S. 2002. "Trust breeds trust: How taxpayers are treated.” Economics of Governance 3(2): 87-99.

Frey, B.S. 1992. "Tertium datur: Pricing, regulation and intrinsic motivation." Kyklos 45(2): 161-184.

Frey, B.S. 1997. Not just for the money: An economic theory of personal motivation. Cheltenham: Edward Elgar.

Hasseldine, J.D. 1998. "Prospect theory and tax reporting decisions: Implications for tax administrators." International Bureau of Fiscal Documentation 52 (11): 501-505.

Kirchler, E.M. 2007. The economic psychology of tax behaviour. Cambridge: Cambridge University Press.

Mumford, A. 2001. Taxing culture. Aldershot: Ashgate.

Puaschunder, J.M. 2018. Intergenerational Responsibility in the 21st Century. Wilmington, US: Vernon Arts \& Science, 2018.

Puaschunder, J.M. 2019a. Corporate and Financial Intergenerational Leadership. Lady Stephenson, Newcastle upon Tyne, UK: Cambridge Scholars Publishing, 2019a.

Puaschunder, J.M. 2019b. Intergenerational Equity: Corporate and Financial Leadership. Cheltenham, UK \& Northampton, MA: Edward Elgar, 2019b.

Puaschunder, J.M. 2020a. Behavioral Economics and Finance: Nudging and Winking to make Better Choices. Springer Nature, 2020a.

Puaschunder, J.M. 2020b. Governance and Climate Justice: Global South and Developing Nations. New York, New York: Palgrave Macmillan. Cham, Switzerland: Springer Nature, 2020b.

Sachs, J.D. 2014. "Climate change and intergenerational well-being." In Bernard, L. \& Semmler, W. (Eds.), The Oxford Handbook of the Macroeconomics of Global Warming, pp. 248-259. Oxford: Oxford University Press.

Schmölders, G. 1960. Das Irrationale in der öffentlichen Finanzwirtschaft. Frankfurt am Main: Suhrkamp.

Stroebe, W. \& Frey, B.S. 1982. "Self-interest and collective action: The economics and psychology of public goods." British Journal of Social Psychology 21(2): 121-137.

Tyler, T.R. \& De Cremer, D. 2006. "How do we promote cooperation in groups, organizations, and societies?" In P.A.M van Lange (Ed.), Bridging social psychology. Benefits of transdisciplinary approaches, pp. 427-433. Mahwah: Lawrence Earlbaum.

The World Bank 2015a. Report. Washington DC: World Bank.

The World Bank 2015b. Green bonds attract private sector climate finance, World Bank Brief. 